\title{
Writing a Teaching Letter
}

Chris Woodward

\author{
Communicated by Harriet Pollatsek
}

Note: The opinions expressed here are not necessarily those of Notices.

Responses on the Notices webpage are invited.

Letters of recommendation that provide evidence of effective instruction are required by most departments as part of the hiring process. Many of us on our departmental hiring committee read some of the teaching letters we received this year with alarm. A number of these letters contained evidence of effective instruction that was anecdotal, circumstantial, or at worst didn't mention teaching at all. The purpose of this note is to offer some suggestions to our colleagues about what I think a helpful teaching letter should contain.

First, a teaching letter should describe what courses the candidate has taught, as well as the other educational activities the candidate has been involved in. These might include mentoring students, supervising undergraduate research projects, or organizing seminars. The letter should also describe the approximate sizes of the classes taught and the candidate's role. Is the candidate experienced at teaching large classes or small tutorials? Was the candidate a recitation instructor or the course head?

Second, the letter should contain exact quotes from students, or at least a description of student feedback. Usually in the American system exact quotes from students are available to copy and paste into the letter from the student

Chris Woodward is faculty in the Department of Mathematics at Rutgers University, New Brunswick. His e-mail address is woodwardc@gmai 1 . com.

For permission to reprint this article, please contact: reprint-permission@ams.org.

DOI: http://dx.doi.org/10.1090/noti1587 evaluations at the end of the semester. If not, the writer may need to ask for help from some former students of the candidate. If there are negative comments, the writer should try to give the committee an idea of why without being unnecessarily harsh.

Third, the letter should contain some numerical data about teaching effectiveness, a description of the scale (typically one to five, with five highest), and the average score in the department. ${ }^{1}$ If no numerical data are given, a hiring committee might reasonably assume that the evaluations were very low. If the candidate taught a large number of classes, the letter might give the range of scores and a description of the most recent few.

Fourth, the letter should contain comments from at least one and preferably at least two faculty members who visited the candidate's class, recitation, or tutorial; this could but need not be the letter writer. How was the board work? The pacing? The spoken English? The mathematical accuracy? The ability of the instructor to engage the entire class? If the letter writer hasn't visited the candidate's class, he or she should try to find a colleague who did. (If no one did, the department is doing a poor job of mentoring.)

${ }^{1}$ Note that evidence of correlation between student ratings and student learning is highly questionable; see [UWG]. However, for the moment, use of student effectiveness scores in hiring and promotion decisions is almost ubiquitous. If the writer objects to the use of such data, and as a result does not include it, this should perhaps be explained in the teaching letter. 
Fifth, the letter should mention at the top any teaching awards. There are certain jobs that are available only to those who have won such a distinction or at least have outstanding teaching credentials, and it helps hiring committees sort the applications if this is mentioned at the beginning.

A letter that addresses all of the above issues positively can produce a substantial upward bump for the candidate in the rankings. It also provides a valuable service to hiring departments.

Finally, the candidate might want to provide the letter writer with as much of the material mentioned above as possible. This might include a list of educational and mentorship activities as well as a list of faculty who have visited classes or tutorials. The letter might be requested in the summer, when the letter writer has time to gather the data and is not yet swamped with letter requests.

\section{Reference}

[UWG] UTTL, White, AND GonzALEz, Meta-Analysis of Faculty's

Teaching Effectiveness: Student Evaluation of Teaching Ratings and Student Learning Are Not Related, Stud. Educ. Eval. 54 (2017).

\section{Photo Credit}

Photo of Chris Woodward by Neepa Maitra.

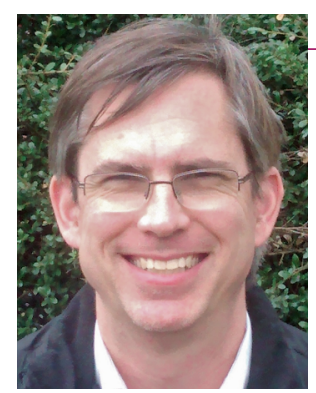

\section{ABOUT THE AUTHOR}

Chris Woodward has served on his department's hiring committee for at least ten years and has served for three years as the faculty member responsible for writing teaching letters for graduate students.

\section{Chris Woodward}

American Mathematical Society

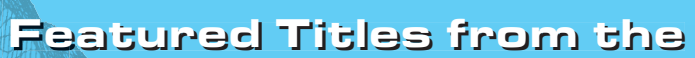

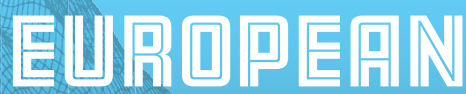

\section{MATHEMPITIERL}

\section{SOEIIETH}

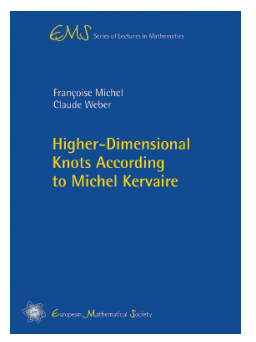

\section{Higher-Dimensional Knots According to Michel Kervaire}

Françoise Michel, Université Paul Sabatier, Toulouse, France, and Claude Weber, Université de Genève, Switzerland

Michel Kervaire wrote six papers which can be considered fundamental to the development of higher-dimensional knot theory. They are not only of historical interest but naturally introduce some of the essential techniques in this fascinating theory. This book provides graduate students with the basic concepts necessary to read texts in higher-dimensional knot theory and its relations with singularities.

EMS Series of Lectures in Mathematics, Volume 28; 2017; 144 pages; Softcover; ISBN: 978-3-03719-180-4; List US\$38; AMS members US\$30.40; Order code EMSSERLEC/28

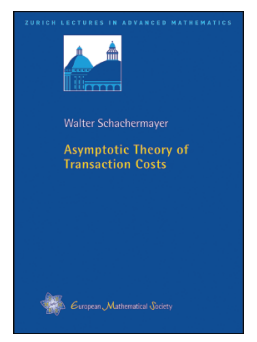

\section{Asymptotic Theory of} Transaction Costs

Walter Schachermayer, University of Vienna, Austria

A classical topic in mathematical finance is the theory of portfolio optimization. These lecture notes present some striking recent results of the asymptotic dependence of the relevant quantities when transaction costs tend to zero.

Zurich Lectures in Advanced Mathematics, Volume 23; 2017; 160 pages; Softcover; ISBN: 978-3-03719-173-6; List US\$38; AMS members US\$30.40; Order code EMSZLEC/23

Publications of the European Mathematical Society (EMS). Distributed within the Americas by the American Mathematical Society.

\section{Explore more titles at} bookstore.ams.org. (iii)AMS Bookstore bookstore.ams.org 